\title{
el cemento portland blanco
}

\author{
der weisse portlandzement
}

W. RIMATHE

(«Koch + Tlefbaus, núm, 37, septiembre 1959, pá. 313,)

En un articulo precedente, el autor expuso los resultados de los ensayos hechos oficialmente con el cemento CBR extrablanco.

El cemento blanco está químicamente emparentado con el cemento portland. En una tabla da el autor la composición química del cemento blanco producido en diferentes países, en comparación con la del cemento portland.

La diferencia típica que se encuentra en todos estos cementos se refiere al contenido en óxido férrico $\mathrm{Fe}_{2} \mathrm{O}_{3}$. El cemento blanco es, pues, desde el punto de vista químico, un cemento portland con un contenido en hierro reducido, lo que explica el color blanco del producto.

Este cemento blanco es el objeto de un anexo de las normas SIA 115, y los ensayos han sido hechos según las prescripciones aplicables al cemento portland.

Las primeras materias para la fabricación del cemento blanco son el caolín y la creta. El proceso de fabricación es el mismo que para el portland en principio, tomando algunas precauciones particulares para obtener el color blanco del producto acabado. Sobre todo, en el horno y durante la molienda se corre el riesgo de introducir en el producto, bien sea carbón, o en la molienda, polvo de acero, que pue- den llegar a impedir la obtención del color blanco deseado. La fabricación debe ser, por tanto, vigilada muy de cerca, Io que explica también la constancia de las otras características técnicas relativas a este cemento blanco.

Entre los resultados estudiados por el autor se encuentra el contenido en "productos inertes" de este cemento, es decir, el contenido de impurezas o de productos añadidos a veces por cualquier motivo al cemento, pero que no participan en el proceso de endurecimiento propiamente dicho. Los ensayos demuestran que la proporción de estos productos es inferior a los límites autorizados por las normas SIA para el cemento portland. A la vez hay que señalar la constancia en los diferentes contenidos, lo que se explica por el cuidado llevado en la fabricación.

En otra tabla se expone la duración de fraguado del cemento blanco (los ensayos han sido llevados a cabo a $18^{\circ} \mathrm{C}$ ). Los tiempos de fraguado encontrados en los catorce años, durante los cuales han tenido lugar estos ensayos, corresponden a Ios exigidos para un cemento portland. Lo mismo puede decirse en lo que concierne a la finura de cemento.

También se resumen los resultados de los ensayos de resistencia; se ha compro- bado que, al cabo de siete días, los resul- 
tados obtenidos son comparables a los exigidos para un cemento portland de alta calidad.

En lo que concierne al color blanco, el autor señala que depende mucho del método empleado. Esta observación es particularmente cierta cuando se quieren comparar los resultados obtenidos en los diferentes países.

Como es el color blanco el que caracteriza particularmente a este producto, se han hecho, con este objeto, una serie de ensayos no habituales para el cemento portland. Se trataba de ver si el color blanco se mantenía, cualquiera que fuesen las condiciones de puesta en obra, mezcla, retracción y ductilidad.

Para la puesta en obra, se ha comprobado que el cemento blanco necesita menos agua que el cemento portland para una misma plasticidad. Es, pues, un elemento que permite obtener, en consecuencia, un mortero u hormigón de una calidad superfor.

Por esto mismo, el mortero de cemento portland blanco segrega menos agua que el cemento ordinario. Este mejora el aspecto futuro del producto una vez endurecido.

La retracción de una pasta pura de cemento es dos veces mayor para el cemento portland ordinario que para el cemento blanco. La adición đe arena tiene por objeto disminuir la retracción de una manera proporcionalmente más importante para el cemento portland ordinario, y los resultados llegan a ser análogos cuando la relación cemento/arena es del orden de $1: 3$ a $1: 6$ en peso o de $1: 2$ a $1: 5$ en volumen.

Un ensayo especial concierne a la ductilidad del cemento.

Un anillo de pasta pura de cemento se colocó alrededor đe un núcleo metálico controlando el tiempo necesario hasta comenzar la fisuración. Los ensayos demostraron que el cemento blanco en pasta pura se agrieta más rápidamente que el cemento portland ordinario. La diferencia disminuye cuando se trata de mortero. u hormigón de cemento blanco.

En lo que concierne al empleo de este cemento blanco, el autor llega a la conclusión de que para obtener un resultado satisfactorio deben emplearse los mismos métodos o principios que para el cemento portland ordinario. Es evidente que la calidad del color obtenido dependerá mucho de la limpieza y de la calidad de las arenas, gravas u otros productos añadidos al cemento blanco.

Para terminar, el autor formula algunas observaciones acerca de los productos colorantes añadidos al cemento $u$ hormigón. La formación de una lechada de cal que al secarse deposita una película blanca sobre la superficie del hormigón, ya ha causado daños en el caso de terrazas, por ejemplo. Al oscurecer un hormigón hay que tener en cuenta, st llega el caso, el hecho de que absorbe calor más fácilmente si está directamente expuesto al sol, y este calentamiento localizado puede arrastrar peligros. Al emplear cemento blanco o claro, los daños proceden en general, bien sea de las gravas sucias o bien cuando la superficie ha sido trabajada con cepillos o utensilios de hierro, en cuyo caso las manchas de óxido que aparecen son debidas al depósito de polvo de acero. En fin, un último motivo puede ser el aceite que a menudo se emplea para el encofrado del hormigón, el cual ensucia a veces las superficies blancas o claras.

Un caso particular es aquel en que, por un motivo de economía, se recubre un hormigón ordinario con un hormigón blanco o un mortero de cemento blanco. Se corre entonces el riesgo de que se formen fisuras y deformaciones, si existen diferencias importantes entre los dos hormigones, en cuanto a composición granulométrica o a cantidad de agua de amasado empleada. En principio, se obtienen mejores resultados cuando la capa de cemento o mortero blanco se coloca estando aún fresco el hormigón que la soporta.

F. S. S. 